http://dx.doi.org/10.18675/1981-8106.vol24.n47.p77-96

\title{
Fazer-se escola fazendo a cidade: as festas dos escolares em Nova Iguaçu (1916-1947)
}

\author{
Amália Dias \\ Faculdade de Educação da Baixada Fluminense - RJ Brasil. \\ amaliadias@gmail.com
}

Educação: teoria e prática, Rio Claro, SP, Brasil - elSSN: 1981-8106

Está licenciada sob Licença Creative Common

\section{Resumo}

Este artigo apresenta resultados de pesquisa de doutorado em que a função social da escola foi investigada a partir dos modos pelos quais as instituições de ensino mobilizavam e participavam da cena pública da cidade. A análise das solenidades e festas realizadas pelas escolas ou das quais estas participavam, a partir da imprensa local e de anotações em mapas de frequência escolar, descortinou um universo produtivo para pensar o entrelaçamento entre a escola e cidade, a função que se pretendia que a escola exercesse sobre a escolarização do espaço e dos sujeitos. Esses eventos, sobretudo as festas escolares e comemorações cívicas, apontam a construção de uma ordenação da escola para a instrução, não apenas em aspectos de letramento, mas também para hábitos de comportamento, valores morais e ritos de cidadania. $\mathrm{A}$ investigação focalizou um município do estado do Rio de Janeiro, Nova Iguaçu. Para além de examinar as imbricações entre cidade e escola, o que se compreende como relevante é o processo concomitante em que escola e cidade se construíam mutuamente e de que modo as práticas educativas ensaiadas nas escolas, por alunos e professores, buscavam, também, educar a população da cidade e enraizar a escolarização enquanto modo de socialização.

Palavras-chave: Escolarização. Cidade. Civismo. Imprensa.

\section{Building a city by building schools: school festivals in Nova Iguaçu (1916-1947)}

\begin{abstract}
This article presents the results of doctoral research in which the social function of the school was investigated with regard to the ways in which educational institutions mobilize and participate in the public scene of the city. The analysis of ceremonies and festivals held by schools or in which they participated, based on the local press and notes in school attendance charts, reveals a productive area that represents the intertwining between school and city and the school's function with regard to the organization of spaces and people. These events, particularly school festivals and public celebrations, point to the construction of a role of the school for instruction not only in aspects of literacy but also in behavioral habits, moral values, and rights of
\end{abstract}


citizenship. The investigation focused on Nova Iguaçu, a city in the state of Rio de Janeiro. In addition to examining the interplay between city and school, the following were also considered relevant: the collaborative process in which school and city are mutually constructed and how educational practices exercised in schools by students and teachers can also be educational for the city's population, thereby establishing schooling as a way of socializing.

Keywords: Schooling. City. Civility. Press.

\title{
Hacerse escuela haciendo la ciudad: las fiestas de los escolares en Nova Iguaçu (1916-1947)
}

\begin{abstract}
Resumen
Este artículo presenta los resultados de investigación de doctorado en que se investigó la función social de la escuela a partir de los modos por los que las instituciones de enseñanza movilizaban y participaban de la escena pública de la ciudad. El análisis de las solemnidades y fiestas realizadas por las escuelas o de las que estas participaban, a partir de la prensa local y de anotaciones en mapas de frecuencia escolar, descortinó un universo productivo para pensar el entrelazamiento entre la escuela y ciudad, la función que se pretendía que la escuela ejerciera sobre la escolarización del espacio y de los sujetos. Esos eventos, sobre todo las fiestas escolares y conmemoraciones cívicas, apuntan la construcción de una reglamentación de la escuela para la instrucción, no apenas en aspectos de alfabetización, sino también para hábitos de comportamiento, valores morales y ritos de ciudadanía. La investigación se concentró en un municipio del estado de Rio de Janeiro, Nova Iguaçu. Más allá de examinar las imbricaciones entre ciudad y escuela, lo que se comprende como relevante es el proceso concomitante en que escuela y ciudad se construían mutuamente y de qué modo las prácticas educativas practicadas en las escuelas, por alumnos y profesores, procuraban también, educar a la población de la ciudad y enraizar la escolarización en cuanto a modo de socialización.
\end{abstract}

Palabras clave: Escolarización. Ciudad. Civismo. Prensa.

\section{Introdução}

As pesquisas produzidas no campo da história da educação constatam que, em diferentes épocas, as instituições escolares participam de experiências engajadas na construção da identidade nacional e cívica dos alunos, por meio de disciplinas escolares, de material didático pertinente, de eventos e datas celebradas no interior das escolas ou no espaço externo. O tema da cidadania, com lembra Luciano Faria Filho é um "elo por excelência" entre cidade e escola (FARIA FILHO, 2005, p.32). 
Cidade e escola foram espaços convocados a servir de cenário e a encenar a experiência de construção da cidadania, em diversos contextos e apropriações. Ao longo do século XIX, porém, além das escolas estarem presentes nas festas urbanas, houve um processo de escolarização desses eventos, e as festas cívicas tornaram-se principalmente festas escolares: "no século XX, a festa cívica se transforma em um momento privilegiado de a escola ocupar a cena da cidade. Nas festas, e pelas festas, a escola se mostra como educadora da infância e da juventude e, sobretudo, dos habitantes da cidade, inclusive de seus quadros dirigentes" (FARIA FILHO, 2005, p.34).

Por isto, os eventos promovidos pelas instituições de ensino ou a presença dos escolares em eventos locais são fontes importantes para a análise das funções sociais que a escola exerce em seu meio. Na pesquisa sobre as funções sociais dos processos de escolarização primária e secundária, em um município do estado do Rio de Janeiro, constatou-se, a partir da análise das fontes, tanto a participação das escolas em eventos da região, quanto a elaboração de eventos próprios das escolas que eram significados como importantes para a vida da cidade.

A imprensa local foi um recurso de registro das interações entre instituições de ensino e seu entorno. Não se trata, porém, de catalogar e descrever como as festas dos escolares se reproduziam no município. Mas, sim, pela escala de observação construída, interrogar de que forma as instituições de ensino mobilizavam a gestação da cidade. Quais as formas de interação entre as escolas e o lugar, com outros atores materiais e sujeitos - que configuravam o espaço público urbano? Em que medida os processos de escolarização permitiam conhecer o desenvolvimento histórico do lugar?

A análise dos tipos de eventos escolares ocorridos, entre as décadas de 1910 e 1940, revela a construção de espaços de sociabilidade que convidavam a sociedade local a prestigiar os atos da vida escolar, assim como o progressivo enraizamento do aparato escolar na localidade. A escola era concebida como um equipamento, um ingrediente indispensável do desenvolvimento local, um instrumento de construção da Nova Iguaçu. ${ }^{1}$

Num segundo momento, ocorreu a intensificação das festas dos escolares promovidas no espaço público, em função do calendário do Estado Novo (1937-1945), no qual se percebe que as escolas, além de participar das sessões cívicas, tornam-se protagonistas destes eventos, escolarizando tais atos da vida pública. É possível examinar ainda, como, através das festas dos escolares, as imbricações entre os

\footnotetext{
${ }^{1}$ Denominação do distrito-sede a partir de 1916. Todo o município passaria à denominação de Nova Iguaçu, provisoriamente pelo Decreto-lei n. 392-A, de 31 de março de 1938 e definitivamente a partir da reforma da divisão territorial do estado do Rio de Janeiro, pelo Decreto n. 641 de 15 de dezembro de 1939. Coleção de Leis do Estado do Rio de Janeiro. APERJ.
} 
interesses dos grupos dirigentes locais e a construção do Estado Nacional encontravam-se no cenário do município. Constituía-se a esfera de atuação estatal engendrando ações coletivas, construindo e reconstruindo espaços, moldando relações, corpos e sensibilidades, com a colaboração da instrução escolar nos modos de organizar a cultura local.

\section{Fazer-se escola compondo a cena da cidade}

A escala do município como posição de análise para investigar os processos de escolarização oferece meios de observar a função social da escola como produtora de identidades sociais e organizadora da cultura (para além da escola), num contexto histórico específico (não necessariamente homogêneo), em que é possível encontrar a construção de práticas importantes de intercâmbio entre cidade e escola, entre política e educação. No programa de pesquisa proposto por Luciano Faria Filho é fundamental a investigação da função social da escola:

\footnotetext{
Isto significa entender que a escola não age apenas intramuros, e sim tem uma ampliada atuação social na medida em que funciona como uma instituição que produz, divulga e legitima identidades, competências e modos de vida, ao mesmo tempo em que deslegitima outros (FARIA FILHO; BERTUCCl, 2009, p.14).
}

Portanto, o estudo dos processos de escolarização abrange considerar as funções da escola enquanto organizadora da cultura, de como a instituição se instrumentaliza para tal, observar a "cultura escolar em ação" e as tensões desse processo:

\footnotetext{
[...] a escolarização envolve, também, uma ação mais ou menos deliberada de educação das sensibilidades, valores e habilidades características do sujeito educado. No entanto, longe de qualquer idealização, estas dimensões da formação devem ser percebidas como estando intimamente relacionadas ao conjunto das experiências dos sujeitos (FARIA FILHO; BERTUCCI, 2009, p.14).
}

Um dos modos de acessar as formas pelas quais a escola organiza-se e organiza a cultura local é pesquisar na imprensa local por quais formas as instituições escolares se inscreviam na vida da localidade. O campo da pesquisa em história local e em história da educação tem tratado da importância da imprensa jornalística como objeto e fonte de pesquisa (CARVALHO; ARAUJO; GONÇALVES NETO, 2002).

O Jornal Correio da Lavoura foi fundado em 1917, no distrito-sede do município, comprometido com as bandeiras da lavoura, higiene e instrução. Era de supor que suas páginas guardariam espaço para os assuntos relacionados às instituições escolares da região. 
Na construção da hegemonia, a imprensa é um recurso de defesa de propostas e visões de mundo, e sua ação busca disseminá-las. É notável o Jornal exercer essa função educativa pela forma como, por seus artigos, viabilizava a voz e a prática de sujeitos e experiências que buscavam disseminar instituições escolares e práticas educativas no município. $E$ isso não ocorria de modo aleatório, porque os setores letrados daquela sociedade, mas, também, os que podiam ouvir comentários, conversas etc. sabiam da função da imprensa enquanto partido de interesses, plataforma de defesas e combates, como já haviam demonstrado as campanhas abolicionista e republicana. É necessário, portanto, também compreender historicamente o jornal local em suas bandeiras, na forma como se inseria na localidade e por quais lentes noticiava a cidade.

De fato, ao lado das denúncias por ampliação do número de matrículas e criação de escolas, das opiniões sobre as funções do ensino, da propaganda sobre a importância da instrução para o progresso moral e econômico local, diversas notas e densas descrições do Correio da Lavoura cobriam acontecimentos nas escolas do munícipio.

Para o trabalho com a imprensa, o procedimento metodológico adotado foi o rastreamento, digitalização, transcrição e análise das matérias pertinentes identificadas no jornal, em todos os números semanais entre os anos de 1916-1950.

Ao final da década de 1910 e ao longo dos anos de 1920, o processo de avaliação dos alunos $\mathrm{e}$ as festas pelo encerramento do ano letivo foram constantemente noticiados nas páginas do semanário. $O$ transcurso dos exames finais, a composição das bancas examinadoras e a lista dos alunos promovidos eram divulgados a cada fim de ano. Nos eventos específicos das escolas, a escolarização dos alunos era reverenciada com o anúncio dos resultados dos exames. As famílias, os representantes do poder público e da imprensa eram convidados a assistir a esses eventos, como as exposições públicas dos trabalhos escolares. ${ }^{2}$

Ainda que um calendário escolar mais extenso de comemorações e solenidades cívicas tenha sido adensado no período pós-1930, muitas preocupações e práticas estavam presentes nos anos de 1910 e 1920, e parte de suas formas rituais perduraram nas décadas posteriores. O engajamento das agências estaduais de

\footnotetext{
2 PELA INSTRUCÇÃO, 13 dez 1917; ANCHIETA, 13 dez 1917; ANCHIETA, 20 dez 1917; PELA INSTRUCÇÃO, 20 dez 1917; EXAMES, 27 nov 1919; MESQUITA, 04 dez 1919. ENSINO PRIMÁRIO, 02 dez 1920. EXAMES, 16 dez 1920; COLLEGIO PARIZ, 16 dez 1920. EXAMES, 17 nov 1921. EXAMES, 08 dez 1921; EXAMES, 22 dez 1921; EXAMES, 14 dez 1922; EXAMES ESCOLARES, 22 nov 1923; EXAMES ESCOLARES, 29 nov 1923; EXAMES ESCOLARES, 13 dez 1923; OS EXAMES NAS NOSSAS ESCOLAS, 20 nov 1924. ENCERRAMENTO DE AULAS, 26 nov 1925; EXAMES E EXPOSIÇÃO DE TRABALHOS, 03 dez 1925; EXAMES, 10 dez 1925; EXAMES, 16 dez 1926; EXAMES, 23 dez 1926; EXAMES, 30 dez 1926; ENCERRAMENTO DAS AULAS, 20 dez 1928; EXAMES, 10 jan 1929; EXAMES, 17 jan 1929; EXAMES DE PROMOÇÃO NA 2a ESCOLA MIXTA DE IGUASSU, 12 dez 1929; EXAMES FINAIS DE PROMOÇÃO DA 33 ESCOLA MISTA DE N. IGUASSU, 26 dez 1929.
} 
fiscalização do ensino para a inclusão de comemorações cívicas nas escolas era replicado pelo Jornal. Em setembro de 1917, sob o título da matéria A ideia de Patria, era transcrita uma circular da Diretoria dos Negócios do Interior e Justiça do estado, enviada aos superintendentes do ensino em todos os municípios, para que estes repassassem aos professores a ordem de explicar aos alunos, "visando fortalecer-lhes o civismo e o espirito de nacionalidade", os motivos da data da Independência do País, "procurando desenvolver-lhes o amor à Patria e o culto à memoria d'aquelles que viveram para o engrandecimento della" ${ }^{3}$ Em 1919, há descrições de "festejos civicos" realizados na cidade, sob a direção do professor da "1a escola publica masculina", Augusto José Rodrigues da Silva Junior. ${ }^{4}$ Do evento participaram "cavalheiros" e famílias "pertencentes a nossa melhor sociedade". Houve o hasteamento do pavilhão nacional, com o canto do hino nacional, do hino da Bandeira e do hino da República pelos alunos. O professor falou sobre a data e senhoritas e alunas recitaram poesias, sonetos e monólogos. Os alunos também demonstraram exercícios de ginástica sueca. Após encerramento dos festejos no edifício da 1a escola masculina, o professor, seus alunos e auxiliares visitaram a 1a escola mista e a 1a escola feminina, sendo então executados novamente o hino nacional e o hino da bandeira. Também houve recitativo de poemas pelos alunos nas escolas visitadas. Á noite, o professor Augusto José Rodrigues ofereceu na sua residência uma sessão literária seguida de grande baile ${ }^{5}$

Em coluna de primeira página, o tema do Ensino Civico era defendido pelo Jornal em 1919: "Pelo que temos dito innumeras vezes o conhecimento do ensino civico faz com que crianças e adultos tenham sciencia dos grandes feitos dos nossos heroes (...)". Ao dotar as pessoas de instrução, acreditava-se ser possível desfazer a situação pela qual se fechava o comércio, à revelia da compreensão do motivo dos feriados: "A nossa historia encerra as mais belíssimas epopéas [...] É necessario os poderes públicos, secundados por elementos particulares, desenvolverem a mais intensa propaganda em prol do ensino cívico" ${ }^{6}$

Nos anos de 1920, além da ritualização das atividades escolares, a Festa da Bandeira e o Dia da Árvore constituíam as datas mais comemoradas nas escolas em Iguaçu. A comparação do relato das comemorações pelo Dia da Árvore nas escolas públicas da cidade revela um mesmo programa de hinos, bailados e recitativos de poesias, discursos sobre a importância da data, "o culto pela arvore" e o plantio de mudas. Em 1926, além do programa executado em cada escola, houve reunião de algumas instituições na Praça Ministro Seabra, com a presença da imprensa local, de populares e "representantes de diversas classes", onde foi repetido o programa ensaiado nas escolas. ${ }^{7}$ Naquele mesmo ano, o Jornal descrevia a Festa da Bandeira nas

\footnotetext{
${ }^{3}$ A IDEIA DE PATRIA, 06 set 1917, pág.1.

${ }^{4} 7$ DE SETEMBRO. COMO A GRANDE DATA FOI COMMEMORADA NESTA CIDADE, 11 set 1919.

${ }^{5} 7$ DE SETEMBRO. COMO A GRANDE DATA FOI COMMEMORADA NESTA CIDADE, 11 set 1919.

${ }^{6}$ ENSINO CIVICO, 16 out 1919, pág 1.

${ }^{7}$ A FESTA DA ARVORE, 07 out 1926.
} 
escolas da cidade, a partir do "programma de festas" da 6a escola mista, "dirigida" pela professora Venina Corrêa Torres. A solenidade contou com a assistência de "nossas autoridades, muitas exmas famílias e mais pessoas gradas". Levados pelas professoras, os alunos realizaram no edifício da Prefeitura o juramento à Bandeira. O prefeito e professores discursaram e procedeu-se à execução do hino nacional. Voltando à escola, o prefeito distribuiu prêmios aos alunos "que mais se distinguiram por sua applicação e comportamento". Outros hinos foram entoados pelos alunos, assim como houve uma sessão literária, "prolongando-se as festas por quasi (sic) todo o resto do dia". Nas escolas mistas das ruas Dr. Thibau e Madureira (no distrito-sede) também foram realizadas "solenidades civicas", com a participação de escoteiros que "abrilhantaram o acto". Os alunos, "bem ensaiados", cantaram hinos, e os professores discursaram sobre a "festividade". A matéria era encerrada repetindo o apoio do Jornal a este tipo de evento, parabenizando aos professores pelo êxito dos festejos e "pelo exemplo de civismo dado aos seus jovens alumnos". ${ }^{8}$

Ao que parece, a citação pelo Jornal dos nomes das professoras e dos alunos participantes consistia numa forma de tributar certa distinção aos mesmos, pelo êxito dos eventos realizados.

A constância e a minúcia das descrições apresentadas pelo Jornal sobre os exames escolares, o encerramento do ano letivo, as exposições de trabalhos escolares e a realização de solenidades cívicas não deve ser compreendida apenas pela presença de um representante do Jornal em cada evento, geralmente convidado pela escola, mas, também, pela importância conferida pelo Jornal a essas ocasiões. Noticiar os eventos em escolas era dar a ver o nível de organização da sociedade local, a presença de instituições de ensino, de professores dedicados e de alunos bem sucedidos. Dialeticamente, tornar os exames finais em atos solenes, premiar os alunos, convidar autoridades políticas, famílias e imprensa, era um meio de projetar e enraizar os rituais escolares na vida social, envolvê-los de expressividade, inscrevê-los na cidade. Preparar os alunos para execução de cânticos, hinos, preleções, exercícios de ginástica, desfiles etc. eram meios de disseminar, via escolas, concepções de mundo, de comportamento, de cidadania, de nacionalismo, que se buscava enraizar em toda sociedade.

Segundo Marta Carvalho, as festas escolares eram prescritas em função da "eficiência pedagógica" que poderiam comportar sobre os escolares e sobre o meio social em que funcionava a escola, mobilizando experiências de representação ou evocação de atos que deveriam ser imitados, apreciados, receber e perceber a aprovação social das realizações encenadas, constituindo lições vividas (CARVALHO, 1998, p. 178-179). Em sua análise sobre as práticas comemorativas realizadas pela Associação Brasileira de Educação, na década de 1920, a autora adverte que, ainda que

\footnotetext{
${ }^{8}$ FESTA DA BANDEIRA, 02 dez 1926.
} 
fossem de diversos temas e variadas formas, e que cada evento parecesse ser uma prática singular e pontual que se esgotava no próprio ato, na verdade, esses episódios "tecem uma rede entre si pela repetição dos mesmos agentes, os mesmos em várias situações, e, ainda, pela equivalência de regras de procedimento" (CARVALHO, 1998, p.181). Pretendia-se que o civismo ensaiado nas escolas servisse de "fôrma" dos modos de educação a incutir, para que a educação colaborasse na criação de uma disciplina consciente e voluntária sem emprego da força física (CARVALHO, 1998, p.150-151).

\section{A escolarização das festas cívicas}

Investigar o sentido de cívico que aparece nas descrições dos eventos com a participação das escolas implica conhecer o que significava civismo no contexto específico da época. O nacionalismo era tema relevante nas escolas desde a década de 1910. As comemorações de datas históricas, atividades e práticas integravam o cotidiano escolar, mas, segundo Carlos Bertolini (2000) portavam o estatuto de atividades complementares às atividades escolares, mantinham um caráter de exterioridade face às práticas escolares cotidianas. No trabalho empírico na pesquisa com o Jornal é, de fato, constatada a presença cotidiana das festas escolares em Nova Iguaçu desde fins da década de 1910, sendo, também, algumas movidas pelo caráter diretamente cívico, se cívico estiver compreendido como vinculado à noção de nação, de pátria, da perspectiva do nacional.

Marta Carvalho (1998), ao examinar o discurso cívico promovido no interior da Associação Brasileira de Educação, lida com uma compreensão mais alargada do termo e demonstra como a questão educacional foi instrumentalizada como uma questão cívica. Revestida da função organizadora que o tema do civismo acionava, a ação educacional colaborou na constituição de um modelo, de um perfil de cidadão condizente com as expectativas de exercício de cidadania prescritas (CARVALHO, 1998, p.137). A ação educacional movida pelas projeções da insuficiência do povo, caracterizado como amorfo, doente, improdutivo, projeções estas gestadas na organização de um pensamento social autoritário ao longo da Primeira República, evidencia a contribuição da escolarização na produção, "no movimento, de dispositivos de sustentação de modelos políticos fortemente excludentes" (CARVALHO, 1998, p.138).

Ao longo da década de 1930, a relação entre civismo, patriotismo, nacionalismo e escola se modifica (BERTOLINI, 2000). A associação entre patriotismo e educação gerou o civismo de novo tipo divulgado a partir do espaço escolar, em que o civismo deixava de ser tema complementar e assumia centralidade na organização das atividades escolares. Para este fim, foi atribuído à educação o papel central de ensino de conteúdos e práticas que deveriam criar o cidadão destinado a construir o futuro virtuoso do país. Esse movimento transbordava o espaço interno da escola, porque o 
governo lançaria mão com frequência do espaço urbano como sucedâneo da participação pública e do exercício das liberdades civis (BERTOLINI, 2000).

O que se compreende, no exame das fontes de pesquisa, é que, no pós-1930, a construção da ideia de nação será cada vez mais, no interior das instituições escolares e nas comemorações públicas, identificada com o civismo. O civismo é subordinado, no interior de uma articulada ação político-cultural do governo de Getúlio Vargas, à certas práticas e concepções de nacionalidade. Sob a ótica da ação governamental da União no pós-1930, "a formação da nacionalidade era entendida como algo que dependia da construção de certas práticas disciplinares de vida que, pouco a pouco, fossem introjetando no cotidiano dos cidadãos a consciência de vida comum, a consciência cívica" (SCHWARTZMAN; BOMENY; COSTA, 2000, p.92). Portanto, a maior incidência de registros de solenidades no pós-1930 e durante o Estado Novo, verificada em Nova Iguaçu, é sintomática dos investimentos, feitos no período, para a construção de um calendário escolar vinculado a disseminar, via escolas, práticas e memórias relacionadas à formação da nacionalidade.

Nos anos iniciais da década de 1930, o Correio da Lavoura acompanhava e valorizava, constantemente, a criação do Ginásio Leopoldo, instalado no distrito-sede. A instituição recebeu subvenção da prefeitura e acolhia o ensino primário e o curso ginasial, nas seções de curso comercial e secundário. Os eventos promovidos pela escola foram noticiados, como os espetáculos teatrais, festivais de caridade e a celebração de datas nacionais, comemorações cívicas, recitais, olimpíadas esportivas, além do aniversário da instituição, que passou a ser comemorado juntamente com o Dia de Tiradentes. ${ }^{9}$

As escolas públicas do município também se apresentavam no repertório de eventos da cidade. Em 1931, a festa da primavera ocorreu pela concentração de cerca de mil crianças na Praça dr. João Pessoa, à convite do prefeito, Sebastião Arruda Negreiros. "Autoridades locais, pessoas de destaque e exmas famílias" prestaram assistência ao evento, que contou com plantio de mudas, discursos do prefeito e de estudantes. Além dos alunos do Grupo Escolar, alunos de outras cinco escolas públicas participaram do evento ${ }^{10}$

A festa parece ter sido um ensaio para a parada escolar advinda no mês seguinte. Tratava-se de comemoração da cidade pelo primeiro aniversário da Revolução de 1930. A parada escolar integrava o grande programa de festejos. Previase a presença de todas as escolas públicas e particulares do município que deviam se

\footnotetext{
${ }^{9}$ GYMNASIO LEOPOLDO, 23 out 1930; GYMNASIO LEOPOLDO. SEU PROGRAMMA FESTIVAL CIVICO E DE CARIDADE, 13 ago 1931; GYMNASIO LEOPOLDO, 20 ago 1931; GYMNASIO LEOPOLDO. COMMEMORAÇÃO CÍVICA DE 7 DE SETEMBRO, 03 set 1931; GYMNASIO LEOPOLDO. SEU PRIMEIRO FESTIVAL TEATRAL, 27 ago 1931.

${ }^{10}$ FESTA DA PRIMAVERA, 24 set 1931.
} 
concentrar na praça dr. João Pessoa, em lugares demarcados por escola. Os alunos e professores das escolas de Queimados, Nilópolis, Austin, Mesquita e Morro Agudo (distritos do município de Iguaçu) seriam transportados por trens especiais, não sendo obrigatório o uso de uniforme, cabendo às crianças levarem a sua própria merenda e a cada escola apresentar recitativos ou discursos alusivos à data. ${ }^{11}$

Ao comentar os festejos do aniversário da "Revolução" no país, na capital federal, e de "varias festividades promovidas pelo governo municipal" em Iguaçu, o Jornal destacava, na cidade, "a que mais viva impressão deixou no espírito publico a grande concentração das Escolas estaduaes, municipaes e particulares do municipio", na Praça João Pessoa. ${ }^{12}$

$\mathrm{Na}$ descrição detalhada do episódio, incluíam-se os hinos entoados pelos alunos, o discurso do prefeito Arruda Negreiros e o agradecimento deste ao concurso prestado pelas escolas ao evento. Foi inaugurado o jardim da praça "util e magnifico melhoramento com que acaba s.s. de concorrer para a esthetica da cidade". Além dos discursos e recitativos, os alunos participaram do desfile pela rua Getúlio Vargas. As comemorações prosseguiram ao longo do dia, com sessão cívica no Cine Verde, com participação de alunos de escolas da cidade. Os festejos noturnos deram-se no "novo logradouro publico bem iluminado", com a presença de famílias e populares que apreciaram a banda de música, alojada no coreto local. Enquanto isto um baile acontecia no salão do Fórum. ${ }^{13}$

Esse evento é bastante simbólico do que se está buscando destacar sobre a participação das escolas na vida social urbana. As escolas levavam práticas ensaiadas, da escola para as ruas, inscrevendo-se como atores em momentos considerados importantes pela sociedade local. A presença dos escolares no evento político de comemoração do novo regime, na inauguração da praça com o nome do político cujo assassinato é aludido como estopim do movimento de 1930, o desfile pela rua recéminaugurada pelo chefe do Governo Provisório com seu próprio nome, são eventos que possibilitam refletir sobre a função social da escola para além de seu universo interno. A forma ensaiada como essas escolas participavam, em lugar de destaque, previamente demarcado, com participações de oratória e demonstração artística, sinalizam a intenção de que essas instituições produzissem e representassem um novo ordenamento dos sujeitos e dos usos dos espaços.

Comparativamente com os anos anteriores, a partir de 1935 houve um aumento expressivo da cobertura do Jornal sobre eventos, solenidades, festas escolares, sessões cívicas. Isto se observa tanto pelo maior número de eventos quanto pela extensão dos mesmos. Essa observação vai ao encontro do registro das

\footnotetext{
${ }^{11}$ GRANDE PARADA ESCOLAR, 22 out 1931.

${ }^{12}$ O DIA DA VITÓRIA, 29 out 1931.

${ }^{13}$ O DIA DA VITÓRIA, 29 out 1931.
} 
solenidades nos mapas de frequência de Nova Iguaçu ${ }^{14}$. Os mapas de frequência do serviço de inspeção estadual consistiam em documentos preenchidos pelos professores das escolas, fornecendo as informações requeridas em diversos campos dispostos no documento impresso. Os mapas deveriam ser enviados mensalmente aos inspetores do ensino da respectiva região escolar em que se inseria o município onde funcionava a escola.

O procedimento metodológico adotado foi a digitalização de todos os mapas escolares dos distritos de Iguaçu entre 1929-1950 e, posteriormente, a transcrição, comparação, análise e sistematização dos dados coletados por campos de informação selecionados.

Os registros das solenidades e eventos nos mapas de frequência estão situados entre os anos de 1935 e 1949 e foram predominantes as solenidades de motivação cívica. As datas repetidamente citadas foram a Semana ou Dia da Criança, 7 de setembro, 15 e 19 de novembro, a Semana ou Dia de Duque de Caxias, e, em agosto, o dia da Árvore. O dia da Abolição, o aniversário da instauração do Estado Novo, o aniversário do presidente Vargas também são constantemente lembrados. $O$ dia ou a semana da Asa, o dia de Tiradentes, o dia do Pan-Americanismo e a vitória dos países aliados na 2o Guerra, assim como o centenário do Barão do Rio Branco (1945), também são eventos registrados em algumas escolas. As solenidades cívicas poderiam ocorrer por iniciativa das escolas ou em associação com outras atividades no espaço público, em função da data celebrada.

No exame das comemorações, nota-se que as solenidades diretamente ligadas ao universo escolar também se tornaram mais densas, com programas mais elaborados. No Grupo Escolar Rangel Pestana, em 1935, o encerramento das aulas foi celebrado na sede do "Sport Club Iguassú", novamente com a participação do coronel Sebastião H. Mattos, Jarbas Cordeiro, diretor de instrução municipal e de representante da folha. O corpo docente apresentou-se quase completo. A diretora Venina Côrrea Torres discursou, assim como alguns alunos e professoras. Homenagens foram prestadas entre a direção, docentes e alunos. A leitura pública das notas dos exames é reveladora da solenidade que se buscava imprimir às atividades escolares. Alunos foram premiados com "a nota máxima de distinção" e um conjunto musical, canto orfeônico e recitativos animaram o final do evento. ${ }^{15}$

Para além da cobertura dos eventos organizados pelas escolas, encontra-se no Correio da Lavoura, para o mesmo período, colunas, crônicas e artigos que voltam a tratar da importância do nacionalismo e do civismo para a educação da juventude. Em 1939, publicava-se um artigo da Diretoria de Propaganda e Publicidade, do governo

\footnotetext{
${ }^{14}$ Fundo Departamento de Educação, Arquivo Público do Estado do Rio de Janeiro.

${ }^{15}$ GRUPO ESCOLAR RANGEL PESTANA, 12 dez 1935.
} 
paulista, intitulado: O conceito de pátria no Estado Novo. ${ }^{16}$ Afirmava-se que o conceito de Pátria havia sido recuperado em seu "verdadeiro sentido", fruto de "uma educação elaborada num período de quase nove anos" e que significava "unidade moral dum país

Explicitava-se, como evidenciam as pesquisas sobre a política educacional do Estado Novo, que foi depositada nas escolas a missão de disseminar certo tipo de civismo, de culto a Pátria e ao Chefe da Nação, de interesse do regime autoritário. 0 artigo exaltava as atitudes do presidente Vargas como exemplos de patriotismo e de união entre povo e governo, por ter agido no sentido de melhorar as condições econômicas e educacionais do povo: "Diante de um quadro de disciplina de nossas energias espirituais e materiais a palavra Pátria tem hoje um significado mais extenso e, por ser tão evocativa, sugere um inadiável compromisso de fé por parte daqueles que verdadeiramente amam este Brasil renovado e poderoso". ${ }^{17}$ (CORREIO DA LAVOURA, 1939, inserir p.2).

Em 1939, na sessão solene no "Gymnasio Leopoldo" pelo Dia da Pátria, que contou com a presença de autoridades locais, o diretor Leopoldo Machado salientou "os deveres das escolas de verdade para a formação do caráter dos seus alunos". ${ }^{18}$ (CORREIO DA LAVOURA, 1939, inserir p.2).

Os festejos eram significados como atividades importantes junto aos alunos e o Jornal destacava a impressão causada pelos desfiles de escolares:

[...] o desfile, principalmente dos alunos do Gymnasio Leopoldo, Curso Iguassu e Collegio Santo Antonio, marcou uma nota de puro civismo nas ruas da cidade, onde se via grande número de famílias, além das autoridades locais. Corpo de ciclistas, de atletas, banda de tambores, guardas de honra, corpo docente, alunos. A formatura dos professores com os seus alunos impressionou pela grande lição de que as lições de civismo, como de tudo, devem vir de cima, dos pais e dos mestres. ${ }^{19}$

Carlos Américo Bertolini (2000, p.51) analisa as formas e os conteúdos das solenidades cívicas do Estado Novo, enquanto encenações do poder e portadoras de um projeto educativo da sociedade, fundamentadas numa "sacralização da política" que ocorreu pela colaboração do Estado com a Igreja Católica. No calendário do regime receberam atenção o Dia da Bandeira Nacional, a Semana da Pátria, o Dia de Tiradentes e a Proclamação da República. Foram acrescidos o Aniversário da Revolução de 1930 e do Estado Novo, a Solenidade em Memória dos Mortos na pejorativamente denominada Intentona Comunista, além da transfiguração do "Dia do Trabalhador" em Dia do Trabalho, o Dia Nacional da Juventude (comemorado na data de aniversário do

\footnotetext{
${ }^{16}$ O CONCEITO DE PÁTRIA NO ESTADO NOVO, 07 set 1939.

${ }^{17}$ O CONCEITO DE PÁTRIA NO ESTADO NOVO, 07 set 1939.

${ }^{18}$ DIA DA PÁTRIA, 14 set 1939.

${ }^{19}$ DIA DA PÁTRIA, 14 set 1939.
} 
Presidente), a Parada da Mocidade e da Raça (ao longo da Semana da Pátria), o Dia da Criança, e as homenagens a Caxias, Tiradentes, Barão do Rio Branco, entre outros vultos da pátria (BERTOLINI, 2000).

As matérias do Jornal e as anotações nos mapas de frequência evidenciam que as escolas em Iguaçu e as lideranças políticas locais compartilharam dessas práticas em que as escolas elaboravam, participavam, conduziam e repetiam, continuadamente, rituais e práticas que almejavam educar politicamente essas populações, de forma a incutir um nacionalismo, revestido de caráter religioso, devotado à pátria e ao chefe da nação. As associações operadas entre a Igreja católica e o Estado autoritário fomentaram a projeção da nação como objeto de culto, revestida da aura de misticismo e de enlevado devotamento, fosse nos discursos dos ideólogos e partidários do regime, fosse nas práticas culturais das solenidades cívicas (BERTOLINI, 2000, p.53). Parte desse calendário e do formato dos eventos era praticado desde o final da década de 1910, o que revela traços das continuidades das relações entre escola, cidadania e cidade, ainda que diferentes significados tenham revestido diferentes momentos políticos.

Maurício Parada (2003) examina como o Canto Orfeônico e a Educação Física significaram, mais do que a propaganda ou a retórica cívica, práticas disciplinares e pedagógicas que buscavam conformar a juventude a um modelo de cidadão: "a articulação entre as cerimônias e as práticas escolares tornou-se um dos mais importantes locus onde se definiu a participação cívica da juventude durante o Estado Novo." (PARADA, 2003, p.11).

O expressivo volume de matérias sobre festas cívicas nas ruas principais da cidade, com participação central de escolas, em Iguaçu, além de atestar as imbricações entre escola e ordenamento, ou pelo menos, certa teatralização do espaço público, chamou atenção, também, para a repetição dos formatos utilizados, dos sujeitos presentes, na relação com as autoridades locais.

Torna-se evidente o empenho dos dirigentes políticos locais em promover esses eventos, em dar a ver que o município participa, tem modos de demonstrar seu tônus civilizatório, sobretudo pela participação dos escolares nas expressões de culto à pátria, à bandeira, à criança, ao chefe de governo etc. Contudo, apropriações realizadas pelos sujeitos participantes dessas experiências e "sentidos variados" poderiam ser construídos na experiência de aprendizagem que as festas escolares propiciavam (FARIA FILHO, 2005, p.34).

Em geral as datas comemoradas em Iguaçu foram as mesmas do calendário nacional. No exame das matérias, no curso do tempo, nota-se a progressiva intensificação da frequência dos eventos e da extensão dos mesmos. Os motivos cívicos são os mais recorrentes, e seus rituais passaram a permear, também, a 
ritualização das práticas essencialmente escolares, como nas festas de encerramento do ano letivo. Mais do que evidenciar a construção de uma identidade local, ao que parece, é o sentimento de pertença a uma nacionalidade que move esses episódios, com o interesse dos sucessivos prefeitos em demonstrar-se alinhados a certas práticas e concepções de cidadania.

A repetição e a sucessão dos eventos também revela certa pedagogia, que espetacularizava as práticas, teatralizava a participação dos sujeitos, engessava os passos, os ditos, os cânticos, as posturas. Além das repetições, a cada ano, de um conjunto de comemorações pautadas por um calendário escolar, havia, também, uma certa continuidade no formato, ao longo do tempo, na comparação entre os eventos.

A repetição do formato dos eventos buscava ensinar aos alunos, às famílias e à cidade, um modo específico de socialização. Na escala de observação de Nova Iguaçu, é possível acompanhar a realização local, a capilarização, via elites dirigentes, bem como o alcance da política educacional e cultural do Estado Novo, que entrelaçou nacionalismo, civismo e instrução. Tratava-se da configuração de uma ideia de nação, do nacional, que materializava-se nos desfiles escolares, nas sessões cívicas. Movimentos locais que buscavam inserir a região na nação, fazê-la constituir-se em nação.

Pelo trabalho com o Correio da Lavoura, foi possível localizar minuciosas descrições sobre os eventos realizados nas escolas da cidade e do município ou ocorridos com a participação dos escolares. O levantamento realizado no Jornal demonstra a maior frequência de notícias, entre 1917 e 1929, sobre os exames finais e o encerramento do ano letivo nas escolas, as comemorações, entrega de prêmios e a publicação do nome dos alunos promovidos por série. Tais registros foram mantidos nas décadas de 1930 e 1940, mas perderam importância ao lado da maior profusão de eventos cívicos em escolas ou com a participação das mesmas, durante todo o ano escolar.

Foi significativa a ocorrência e a cobertura jornalística das comemorações cívicas realizadas no período do Estado Novo (1937-1945), assim como o registro dessas ocorrências nos mapas de frequência das escolas públicas primárias do município. Tais acontecimentos mobilizavam as escolas municipais, estaduais e particulares do município, instituições de ensino primário, profissional e secundário, com a presença das autoridades locais e das famílias dos alunos. Através da análise das formas como esses eventos ocorriam na cidade de Nova Iguaçu, muitas vezes para além do espaço das escolas, recuperam-se informações e registros das interações ou 
interdições das atividades escolares com o espaço da cidade e com sua ambiência política, cultural e social. É viável, também, pelo trabalho com a imprensa, entrever o sentido desses cultos à pátria e ao chefe do governo como projetos de formação da nacionalidade e a participação dos poderes municipais e de parcelas da sociedade civil fomentando essas atividades.

No cenário urbano do distrito-sede, as funções sociais da escola enquanto organizadora da cultura encontravam um ambiente favorável de expansão, tanto junto aos alunos quanto na encenação, para a população, de novos códigos de comportamento e visões de mundo. A participação das escolas na vida pública da cidade, ocupando e constituindo este espaço nas solenidades, festas cívicas e paradas escolares, alinhava a escola às expectativas de construção da nacionalidade. Tratava-se da configuração de um exercício de cidadania que pretendia incutir uma submissão devotada aos interesses nacionais, à pátria revestida de caráter sagrado e materializada no culto ao chefe do poder federal. Dialeticamente, ainda que de maneira ensaiada e condicionada, a infância e juventude, por meio da escolarização, eram chamadas a participar de experiências de formação política.

Os registros de eventos realizados em escolas, pelas escolas, ou com a participação das escolas, existiam em Iguaçu desde os anos de 1910. Ao transformar em solenidades e teatralizar atos da vida escolar, como os exames finais e a exposição de trabalhos, ao promover as festas do dia da árvore e da bandeira, a escola operava uma valorização, plantava um lugar de relevância de suas atividades no ambiente em que estavam localizadas, inscrevendo a escolarização na vida do lugar. Ao conferir prêmios e aplausos aos alunos e professores, promovia-se a valorização da cultura letrada, da progressão dos estudos e de aspectos da vida cívica.

O que foi possível diferenciar, no pós-1930, é que os motivos nacionais, inscritos e aumentados no calendário, sobretudo no Estado Novo, foram transbordando para a vida pública, tornando-se sempre mais frequentes e compondo as festas cívicas em festas escolares. Os estudantes e seus professores tornavam-se, em suas encenações de cantos, hinos, discursos e marchas, o depósito do futuro que se almejava construir, o avesso do Jeca-tatu (previamente forjado) que se tentava conformar, pela saúde e instrução, aos projetos autoritários de hegemonia em curso. Para estes eventos concorriam tanto as circulares baixadas pelas agências de governo, que buscavam incutir no cotidiano das escolas essas festividades, quanto os convites dirigidos às escolas oriundos dos dirigentes locais, para participação em eventos promovidos na cidade. Interesses locais e nacionais forjavam essas experiências em que a escola disseminava e espelhava modelos de cidadania que se buscava incutir na população. É relevante perceber, ainda, que os festejos cívicos, as exposições e solenidades ampliavam a ação educativa do Estado, portanto, com a participação de diversas agências, entre elas, a escola, a imprensa, a família, os governos locais. 


\section{Referências}

ARQUIVO PÚBLICO DO ESTADO DO RIO DE JANEIRO - APERJ. Decreto-lei n. 392A/1938; Decreto n. 641/1939. In: Coleção de Leis do Estado do Rio de Janeiro. Rio de Janeiro: APERJ, 1938, 1939.

BERTOLINI, C.A. Encenações patrióticas: a educação e o civismo a Serviço do Estado Novo (1937-1945). 2000. Inserir n. de folhas. Dissertação (Mestrado em História) Universidade Federal de Mato Grosso. Cuiabá, 2000.

CARVALHO, M.M.C de. Molde Nacional e Fôrma Cívica: higiene, moral e trabalho no projeto da Associação Brasileira de Educação (1924-1931). Bragança Paulista: EDUSF, 1998.

CARVALHO, C. H.; ARAUJO, J. C. S.; GONÇALVES NETO, W. Discutindo a História da Educação: a imprensa enquanto objeto de análise histórica (Uberlândia-MG, 19301950). In: ARAUJO, J.C.S.; Gatti JR., D. (Orgs.). Novos Temas em História da Educação Brasileira: Instituições Escolares e Educação na Imprensa. 3ed. Campinas, Uberlândia: Autores Associados, EDUFU, 2002. v. I, p. 67-90.

7 de SeTEMBro. como a GRANDE dATA fol commemorada nesta CIDAde. Correio da Lavoura. Nova Iguaçu, ano III, n.130, 11 set. 1919.

A IDEIA DE PATRIA. Correio da Lavoura. Nova Iguaçu, ano I, n.25, 6 set. 1917.

A FESTA DA ARVORE. Correio da Lavoura. Nova Iguaçu, ano X, n.499, 7 out. 1926.

ANCHIETA. Correio da Lavoura. Nova Iguaçu, ano I, n.39, 13 dez. 1917.

ANCHIETA. Correio da Lavoura. Nova Iguaçu, ano I, n.40, 20 dez. 1917.

DIA DA PÁTRIA. Correio da Lavoura. Nova Iguaçu, ano XXIII, n.1.173, 14 set. 1939.

enCerRamento de aUlas. Correio da Lavoura. Nova Iguaçu, ano XI, n.454, 26 nov. 1925.

ENSINO CIVICO. Correio da Lavoura. Nova Iguaçu, ano III, n.135, 16 out. 1919. 
EXAMES. Correio da Lavoura. Nova Iguaçu, ano III, n.141,27 nov. 1919.

EXAMES. Correio da Lavoura. Nova Iguaçu, ano IV, n.196, 16 dez. 1920.

EXAMES. Correio da Lavoura. Nova Iguaçu, ano v, n.244, 17 nov. 1921.

EXAMES. Correio da Lavoura. Nova Iguaçu, ano v, n.247, 8 dez. 1921.

EXAMES. Correio da Lavoura. Nova Iguaçu, ano v, n.249, 22 dez. 1921.

EXAMES. Correio da Lavoura. Nova Iguaçu, ano vI, n.300, 14 dez. 1922.

EXAMES. Correio da Lavoura. Nova Iguaçu, ano XI, n.456, 10 dez. 1925.

EXAMES. Correio da Lavoura. Nova Iguaçu, ano x, n.509, 16 dez. 1926.

EXAMES. Correio da Lavoura. Nova Iguaçu, ano x, n.510, 23 dez. 1926.

EXAMES. Correio da Lavoura. Nova Iguaçu, ano x, n.511, 30 dez. 1926.

EXAMES. Correio da Lavoura. Nova Iguaçu, ano XII, n.617, 10 jan. 1929.

EXAMES. Correio da Lavoura. Nova Iguaçu, ano XII, n.618, 17 jan. 1929.

EXAMES DE PROMOÇÃO NA 2a ESCOLA MIXTA DE IGUASSU. Correio da Lavoura. Nova Iguaçu, ano XIII, n.665, 12 dez. 1929.

EXAMES e EXPOSIÇÃO DE TRABALHOS. Correio da Lavoura. Nova Iguaçu, ano XI, n.455, 3 dez. 1925.

EXAMES escolares. Correio da Lavoura. Nova Iguaçu, ano VII, n.349, 22 nov. 1923. 
EXAMES ESCOLARES. Correio da Lavoura. Nova Iguaçu, ano VII, n.350, 29 nov. 1923.

EXAMES ESCOLARES. CorReIO da LaVoura. Nova IguaÇu, ANO VII, N.352, 13 DEZ. 1923.

EXAMES FINAIS DE PROMOÇÃO DA 33 ESCOLA MISTA DE N. IGUASSU. Correio da Lavoura. Nova Iguaçu, ano XIII, n.667, 26 dez. 1929.

EXAMES FINAIS E DE PROMOÇÃo DOS ALUNOS DA 1a esCOLA MISTA DE NOVA IGUAÇU. Correio da Lavoura. Nova Iguaçu, ano XVI, n.820, 1ํ. dez. 1932.

EXPOSIÇÃO DE TRABALHOS. Correio da Lavoura. Nova Iguaçu, ano XIX, n.978, 19 dez. 1935.

EXPOSIÇÃO DE TRABALHOS ESCOLARES. Correio da Lavoura. Nova Iguaçu, ano XIV, n.716, 4 dez. 1930.

EXPOSIÇÃo de tRABalhos escolares. Correio da Lavoura. Nova Iguaçu, ano XV, n.766, 19 nov. 1931.

EXPOSIÇÃO DE TRABAlhoS eSCOLARES. Correio da Lavoura. Nova Iguaçu, ano XVI, n.820, 1‥ dez. 1932.

EXPOSIÇÃO DE TRABALHOS ESCOLARES. Correio da Lavoura. Nova Iguaçu, ano XVI, n.821, 8 dez. 1932.

EXPOSIÇÃO DE TRABALHOS DA SEGUNDA ESCOLA MISTA. Correio da Lavoura. Nova Iguaçu, ano XV, n.768, 03 dez 1931.

EXPOSIÇÃo de tRABalhos no G.e. RANGel PESTANA. Correio da Lavoura. Nova Iguaçu, ano XIX, n.977, 12 dez. 1935.

FESTA DA BANDEIRA. Correio da Lavoura. Nova Iguaçu, ano X, n.507, 2 dez. 1926.

FESTA DA PRIMAVERA. Correio da Lavoura. Nova Iguaçu, ano XV, n.758, 24 set. 1931. 
GRANDE PARAdA ESCOLAR. Correio da Lavoura. Nova Iguaçu, ano Xv, n.762, 22 out. 1931.

grupo escolar rangel Pestana. Correio da Lavoura. Nova Iguaçu, ano xix, n.977, 12 dez. 1935.

GYMNASIO LEOPOLDO. Correio da Lavoura. Nova Iguaçu, ano XIV, n.710, 23 out. 1930.

GYMNASIO LEOPOLDO. Correio da Lavoura. Nova Iguaçu, ano XV, n.753, 20 ago. 1931.

gYMNASIO LEOPOLDO. SEU PRIMEIRO FESTIVAL TEATRAL. Correio da Lavoura. Nova Iguaçu, ano XV, n.754, 27 ago. 1931.

gymnasio leopoldo. Seu Programma festival Civico e de CARIDAde. Correio da Lavoura. Nova Iguaçu, ano XV, n.752, 13 ago. 1931.

gYMNASIO LEOPOLDO. COMMEMORAÇÃo CÍVICA DE 7 DE SETEMBRo. Correio da Lavoura. Nova Iguaçu, ano Xv, n.755, 3 set. 1931.

o CONCEITO de PÁtRIA NO eSTAdo novo, Correio da Lavoura. Nova Iguaçu, ano XXIII, n.1.172, 7 set. 1939.

O DIA DA VITÓRIA. Correio da Lavoura. Nova Iguaçu, ano xV, n.763, 29 out. 1931.

PELA INSTRUcÇão. Correio da Lavoura. Nova Iguaçu, ano I, n.39, 13 dez. 1917.

PELA INSTRUCÇão. Correio da Lavoura. Nova Iguaçu, ano I, n.40, 20 dez. 1917.

FARIA FILHO, L.M. de; BERTUCCI, L.M. Experiência e cultura: contribuições de E. P. Thompson para uma história social da escolarização. Currículo sem fronteiras, v.9, n.1, p.10-24, Jan./Jun. 2009.2 Disponível em: http://www.curriculosemfronteiras.org/artigos.htm. Acesso em: 10 out. 2009. 
FARIA FILHO, L.M. de. Cultura escolar e cultura urbana: perspectivas de pesquisa em história da educação. In: XAVIER, L.N.; CARVALHO, M.M.C. de; MENDONÇA, AW.; CUNHA, J.L. da (Orgs.). Escola, culturas e saberes. Rio de Janeiro: FGV, 2005. p. 29-37.

PARADA, M.B.A. Educando corpos e criando a Nação: cerimônias cívicas e práticas disciplinares no Estado Novo. 2003. Tese (Doutorado em História) - Universidade Federal do Rio de Janeiro. Rio de Janeiro, 2003.

SCHWARTZMAN, S.; BOMENY, HM.B.; COSTA, V.M.R. Tempos de Capanema. São Paulo: Paz e Terra: Ed. FGV, 2000.

Enviado em Julho/2013 Aprovado em Agosto/2014 